\title{
Clinicopathological Study of Anemia among Female Medical College Students
}

\author{
${ }^{1}$ Dr.Karthikeyan T M, ${ }^{2}$ Dr.Ajeeth Kumar C R, ${ }^{3}$ Dr.Veenaa N N, ${ }^{4}$ Dr. Tamil Selvi \\ ${ }^{I}$ Professor and Head Department of Pathology Karpagam Faculty of Medical Sciences and Research \\ Othakalmnadapam \\ ${ }^{2,3,4}$ Assisstant Professor Department of Pathology Karpagam Faculty of Medical Sciences and Research \\ Othakalmnadapam \\ Corresponding Author:*Dr.Ajeeth Kumar C R
}

\begin{abstract}
Anemia is a very common blood disorder associated with abnormal reduction in hemoglobin, RBC count and hematocrit values below the established reference values. It is very much prevalent and is largely undiagnosed among students in professional institute.

Objectives \& Aim: The objective of this study was tofind out the prevalence of anemia among females in medical college and to classify anemia based on red cell morphology.

Materials and Methods: A cross - sectional medical institutional based study was conducted in the department of pathology. Information regarding diet, anthropometric parameters and menstrual history was obtained through a detailed questionnaire. Hemoglobin and RBC indices were analyzed using Horiba micros Dx auto analyzer.

Results: Out of a total 150 medical students, 98were anemic. 89 had mild and 9had moderate anemia. The mean weight of the students were $55.66 \pm 2.12 \mathrm{~kg}$ (Normal), $53.48 \pm 11.31$ (Mild Anemia) and $47.44 \pm 2.1 \mathrm{~kg}$ (Moderate Anemia). There was a significant difference between weight of women with mild and moderate anemia $(p<0.001)$ and between normal and moderate anemia $(p<0.0001)$ respectively.30.3\% of students with mild anemia and $44.4 \%$ of students with moderate anemia complained of day time fatigability. $23.55 \%$ of students with mild anemia and $33.33 \%$ of students with moderate anemia complained of inability to concentrate in the class. There was a significant association between anemia and duration of menstruation $(p<0.05)$

Conclusion: Prevalence of mild to moderate anemia among young female medical students was very high and is undiagnosed in most of the cases. A co - ordinated effort is needed for dietary modification, counselling, nutritional Supplementation and treatment of menstrual disorder.
\end{abstract}

Keyword: Anemia, Young female medical students.

\section{Introduction}

Anemia is a very common blood disorder associated with abnormal reduction in red blood cell count, hemoglobin $(\mathrm{Hb})$ and hematocrit $(\mathrm{HCT})$ values below the established reference values. Adolescence is a transitional period with a very high metabolic demand ${ }^{1-3}$. During this period with inadequate and improper dietary habits, one is vulnerable to all kinds of nutritional morbidities ${ }^{3,4}$. Anemia remains a major challenge and its prevalence is very high and is mostly undiagnosed in developing countries. Nutritional anemia though global in occasion, is more of a concern in developing countries because of high prevalence in these regions ${ }^{3,5 .}$ India has a high prevalence of iron - deficiency anemia among women. Between $60-70 \%$ of adolescent girls are anemic and can result in poor pregnancy outcome as well as poor academic performance ${ }^{6-8}$. Medical education is a very highly demanding course which imparts serious strain on anemic persons affecting their academic performance and work efficiency?

The principal cause of anemia inyoung woman is excessive blood loss during menses ${ }^{10}$. The present study was undertaken to assess the prevalence of anemia among young female medical student and to plan for effective management strategy.

\section{Material And Methods}

A cross - sectional medical institution based study was carried out in department of pathology at Karpagam Faculty of Medical Science and Research during the month of February - march 2016. The study subjects included 150 young adult female medical students in the age group of $16-19$ yrs. A predesigned selfadministered questionnaire was used after obtaining informed consent ${ }^{9}$.Information on dietary habits, anthropometric measurements and menstrual history was obtained. Classification of grading of anemia was followed as per WHO guideline ${ }^{7}$. Blood samples were collected in the morning through venipuncture and analyzed by Horiba micros Dx auto analyzer inthe department of pathology, Karpagam Medical College for estimation of Hemoglobin concentration,hematocrit, mean corpuscular volume, and mean corpuscular 
hemoglobin concentration. For morphological examination of RBC's. Peripheral blood film was made and stained with Leishman stain.

Results :

In the present study, 150 medical students in the age group of 16-19 years were evaluated.98 students were anemic, out of which 89 students had mild and 9 students had moderate anemia (table-1).The most common type of anemia was microcytic hypochromic anemia with MCV being $71.2 \pm 6 \mathrm{fl}$. The mean weight of students were $55.6 \pm 2 \mathrm{~kg}$ (normal), $53.48 \pm 11 \mathrm{~kg}$ (mild) and $47.44 \pm 6 \mathrm{~kg}$ (moderate) (Table 2). There was a significant difference exists between weight of women with mild versus moderate anemia $(\mathrm{p}<0.001)$ and normal versus moderate anemia $(\mathrm{p}<0.0001)$ (Table 3$) .30 .3 \%$ of students with mild anemia and $44.4 \%$ of students with moderate anemia complained of day time fatigability. $23.55 \%$ of students with mild anemia and $33.33 \%$ of students with moderate anemia complained of inability to concentrate in the class (Table 4).The mean duration of menstruation in women with moderate anemia was 5.2 days. There was no significant difference in the diet between anemic individuals and the normal individuals.

Table-1-Anemia status in Female Medical College Students

\begin{tabular}{|c|c|}
\hline INDICATOR & NUMBER \\
\hline Normal(Hb12-14g/dl) & 52 \\
\hline Mild anemia(Hb $10-11.9 \mathrm{~g} / \mathrm{dl})$ & 89 \\
\hline Moderate anemia $(\mathrm{Hb} 8-9.9 \mathrm{~g} / \mathrm{dl})$ & 9 \\
\hline Total & 150 \\
\hline
\end{tabular}

Tab: 2: Hemoglobin, MCV and Weight and Menstruation status among Females Medical college

\begin{tabular}{|c|c|c|c|}
\hline PARAMETER & NORMAL & MILD & MODERATE \\
\hline Hb mean $(\mathrm{g} / \mathrm{dl})$ & $12.6 \pm 1.3$ & $10.3 \pm 1.2$ & $8.9 \pm 1.3$ \\
\hline Weight $(\mathrm{kg})$ & $55.6 \pm 2.12$ & $53.4 \pm 11.3$ & $47.44 \pm 2.1$ \\
\hline MCV(fl) & $88.19 \pm 4.3 \mathrm{fl}$ & $84.3 \pm 6 \mathrm{fl}$ & $72.44 \pm 5.88 \mathrm{fl}$ \\
\hline Lack of concentration & $16.9 \%$ & $23.59 \%$ & $33.3 \%$ \\
\hline Menstruation & $2-4$ Days & $2-4$ Days & $5-7$ Days \\
\hline
\end{tabular}

Table 3- Correlation of Weight and Anemiaamong Females in Medical College

\begin{tabular}{|l|c|c|c|c|}
\hline & No of students & Percentage & $\mathrm{Hb}(\mathrm{mg} / \mathrm{dl})$ & Weight $(\mathrm{Kg})$ \\
\hline Normal & 53 & 35.1 & $12.6 \pm 1.34$ & $55.66 \pm 2.12$ \\
\hline Mild & 89 & 58.1 & $11.3 \pm 1.27 *$ & $53.48 \pm 11.31$ \\
\hline Moderate & 9 & 5.9 & $8.9 \pm 1.3 *$ & $47.44 \pm 2.1 * * *$ \\
\hline
\end{tabular}

Table 4 Correlation of Diet, Fatigue,Lack of concentration and anemia among Females in Medical College

\begin{tabular}{|c|c|c|c|c|}
\hline \multicolumn{2}{|c|}{ Parameters } & Normal Hb & Mild Anemia & Moderate Anemia \\
\hline \multicolumn{2}{|c|}{ Fatigue (\%) } & 26.4 & 30.3 & 44.4 \\
\hline \multirow{2}{*}{ Diet } & Veg \% & 13 & 12.3 & 12.5 \\
\hline & Non veg \% & 86.8 & 87.6 & 88.9 \\
\hline \multicolumn{2}{|l}{ Lack of concentration } & 16.9 & 23.59 & 33.3 \\
\hline
\end{tabular}

Table -5 Diet and anemia among Females in Medical College

\begin{tabular}{|c|c|c|}
\hline Diet & Vegetarian & Non-Vegetarian \\
\hline Normal & 6 & 46 \\
\hline Mild Anemia & 11 & 78 \\
\hline Moderate Anemia & 1 & 8 \\
\hline Total & 18 & 132 \\
\hline
\end{tabular}

\section{Discussion}

In the present study, the prevalence of anemia was $65.3 \%$. This is similar to the study conducted by Saratha A. et al Studies on anemia in different states of India have reported a prevalence rate of $46 \%-95 \%{ }^{(10-}$ ${ }^{14)}$ In a study by Toteja G S and Singh $\mathrm{P}^{10}$ who obtained data from 16 districts of 11 states via district nutrition projects found a prevalence of anemia among adolescent girls to be as high as $90.1 \%$. All young adult female students should be made aware about the increasing prevalence of anemia during this period and should be subjected to regular checkup forHemoglobin. Several studies have reported successful management of anemia by supplementation of iron and folic acid in their diet. ${ }^{15,16}$ There was a statistical difference between anemia and duration of menstruation highlighting the fact that menstrual abnormalities are common among young women and has to be treated medically. 
The most of common type of anemia in the present study was microcytic hypochromic anemia due to iron deficiency which could be attributed to menstrual loss. There was no statistical difference in the type of diet (veg/Non veg and prevalence of anemia).This could be due to the fact that diet history was obtained by 24 hour recall method that was not adequate to bring out the true association between diet and anemia.Medical education is a highly demanding course which requires a constant attention and focus towards studies. Women with moderate anemia had difficulty in concentration towards studies $(33.3 \%)$ and day time fatigability (44.4\%) which leads to poor academic performances. Kaur et al in their study have documented the role of green leafy vegetables in the prevention of anemia ${ }^{17}$ in adolescent girls. So consumption of green leafy vegetables should be made mandatory to all adolescent girls and the importance of consuming a balanced diet alsoshould be emphasized.

\section{Conclusion}

In the present study, prevalence of anemia among female medical college students were 65.5\%.Among those, only women with moderate anemia had difficulty in concentration (33.3\%) and day time fatigability(44.4\%). There was a strong statistically significant correlation between moderate anemia and duration of menstruation ( $>5$ days). There was also a significant difference between weight of women vs mild \& moderate anemia respectively $(p<0.001)$ and normal \& moderate anemia $(p<0.0001)$ respectively. There was no statistical difference between diet and anemia.

This study highlights the fact that microcytic hypochromic anemia is the most common type of anemia among young women and has to be treated medically followed by proper dietary education and nutritional supplementation to improve their health and also to boost their academic performances.

[1]. WHO. Techn. Rep. Ser., No. 477; 1971

\section{References}

[2]. WHO. World Health Statistics Quarterly, 35:52; 1982.

[3]. Royston, E. WHO. Statistics. 14 35:52; 1982

[4]. WHO. Techn. Rep. Ser., 713; 1984.

[5]. Basu S, Hazarika R and Parmar V. Prevalence of anemia among school going adolescents of Chandigarh. Indian Pediatrics 2007;42:593

[6]. World Health Organization. Iron deficiency anemia. Assessment, Prevention, and Control: A guide for programme managers. UNICEF, United Nations, WHO; 2001

[7]. Anand K, Kant S, Kapoor SK. Nutritional status of adolescents school children in rural North India. Journal of Association of Physicians of India, 2004;52:18-20.

[8]. Bradshaw H and Pande R. The Communication Initiative on July 162004 and December 6 2005, respectively; $1-2$.

[9]. Saratha A,SinghZ,Datta S S, etal.Prevalance of Anemia among young Adult Female students in a Medical Teaching Institution in Pondicherry. Indian Journal of Maternal and Child Health 2010,Oct-Dec;12(4)

[10]. Toteja GS, Singh P. Micronutrient profile in Indian population (part-I) New Delhi; Indian Council Medical Research 2002;131-140

[11]. Kanani S. Combating anemia in adolescent girls: a report from India. Mothers child 1994;13:1-3.

[12]. Pathak P, Singh P, Kapil U, Raghuvanshi RS. Prevalence of iron, Vitamin A and iodine deficiencies among adolescent pregnant mothers. Indian Pediatr 2003:70:296-301.

[13]. Kumar S, Raharatam A. Prevalence of anemia and hookworm infestation among adolescent girls in one rural block of Tamilnadu. Indian J Matern Child Health 1997:8:73-5.

[14]. Sindhu S, Kumari K, Uppal M. Prevalence of anemia among adolescent girls of SC of Punjab. Anthropologists 2005;7(4):265-7.

[15]. Roschnik N, Parawan A, Baylon MA, Chua T, Hall A. Weekly iron supplements given by teachers sustain the hemoglobin concentration of schoolchildren in the Philippines.Tropical Medicine and International health 2004;9(8):904-9.

[16]. Deshmukh PR, Garg BS, Bharambe MS. Effectiveness of weekly supplementation of iron to control anemia among adolescent girls of Nashik, Maharashtra, India. J Health PopulNutr 2008;26(1):74-8.

[17]. Kaur M, Singh K. Effect of health education on knowledge, attitude and practices about anemia among rural women in Chandigarh. Indian J Community Med 2001;26(3):128. 